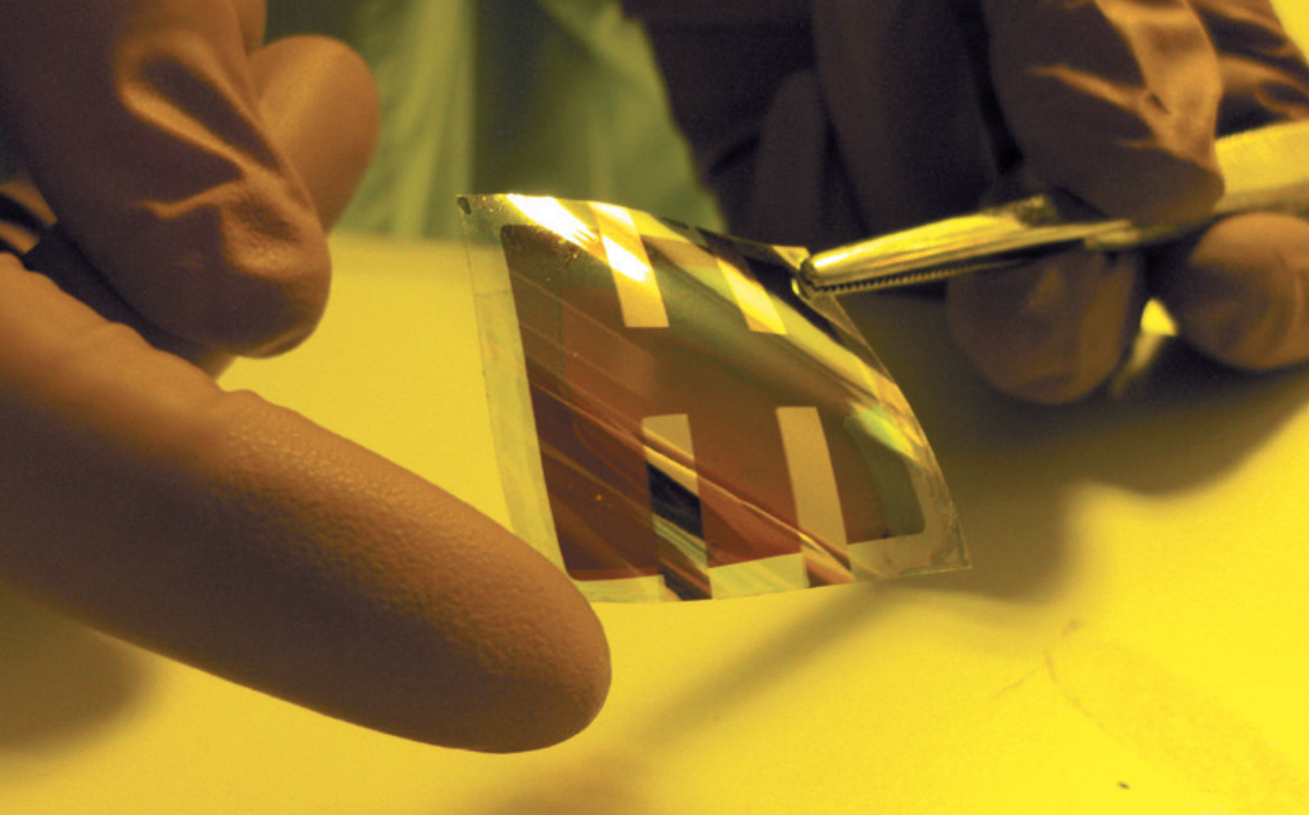

Perovskite solar cells, currently postage-stamp sized, must be scaled up to be practically viable.

SOLAR POWER

\title{
Cheap solar cells tempt businesses
}

\section{Easy-to-make perovskite films rival silicon for efficiency.}

\section{BY RICHARD VAN NOORDEN}

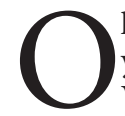

lga Malinkiewicz, a PhD student studying photovoltaics at the University of Valencia in Spain, first heard about perovskites, the latest hope for low-cost solar power, in April last year. Unlike the slabs of purified silicon at the heart of the solar cells that currently dominate the market, perovskites form thin films that are easily made in the lab by mixing together cheap salts. "I couldn't believe it was so simple," says Malinkiewicz, who immediately tried it herself.

A year later, she won a European student innovation prize, for coating flexible foil with perovskites. "After that, my telephone didn't stop ringing," she says. "Investors were asking me all the time if I was going to start a company." By May 2014, the excited 31-year-old had decided to do just that. In the past three months, she has moved from Spain to her native Poland, rented laboratory space in Wrocław, founded the privately backed company Saule Technologies, and rebuffed an offer of $€ 1$ million (US $\$ 1.3$ million) for $10 \%$ of the fledgling firm - although she is yet to complete her $\mathrm{PhD}$.

Malinkiewicz's bold venture epitomizes how fast perovskites have zipped from academic curiosity to the brink of commercialization. In three years, competing research groups have tripled the cells' efficiency, achieving what took decades to accomplish for other solar materials.

Large, commercial silicon modules convert $17-25 \%$ of solar radiation into electricity, and much smaller perovskite cells have already reached a widely reproduced rate of $16-18 \%$ in the lab - occasionally spiking higher. They are expected to top $20 \%$ in a few months, says Sang Il Seok at the Korea Research Institute of Chemical Technology in Daejeon, whose lab holds the current record of $17.9 \%$. "The results so far are truly spectacular," says David Ginley, a researcher at the US National Renewable Energy Laboratory in Golden, Colorado.

The combination of low cost and efficiency means that perovskite cells could, in theory, make solar power - which currently provides less than $1 \%$ of the world's electricity - cheaper to generate than fossil-fuel energy, according to Henry

\section{"I couldn't} believe it was so simple."

Snaith, a physicist at the University of Oxford, UK (see Nature 504, 357-365; 2013). At a conference he convened in Oxford on 11-12 September, perovskite researchers discussed the remaining barriers to the technology's commercial success.

The cells, composed of perovskite film sandwiched between conducting layers, are still about the size of postage stamps. To be practical, they must be scaled up, which causes efficiency to drop. Seok says that he has achieved $12 \%$ efficiency with 10 small cells wired together.

Doubts remain over whether the materials can survive for years when exposed to conditions outside the lab, such as humidity, temperature fluctuations and ultraviolet light. Researchers have also reported that ions inside some perovskite structures might shift positions in response to cycles of light and dark, potentially degrading performance.

Oxford Photovoltaics (Oxford PV), a company that Snaith co-founded, says that its unpublished tests show that the cells can meet industry stability standards if encapsulated in glass, as silicon panels are. By 2017, the company's commercial partners aim to be using perovskites trapped in glass to produce transparent cells that could hug the exteriors of buildings. And on 16 September, Snaith and his colleagues published another way to protect a perovskite cell from heat and moisture, by replacing one of its layers with carbon nanotubes embedded in insulating plastic (S. N. Habisreutinger et al. Nano Lett. http://dx.doi. org/10.1021/nl501982b;2014).

The need for this engineering might create another setback, says Arthur Nozik, a chemist at the University of Colorado Boulder. After plummeting in past years, the price of crystalline silicon modules - which make up 90\% of the solar-cell market - has levelled off but is expected to keep falling slowly. As a result, most of the cost of today's photovoltaic systems is not in the material itself, but in the protective glass and wiring, racking, cabling and engineering work.

When all these costs are factored in, perovskites might save money only if they can overtake silicon in efficiency. In the short term, firms are focusing on depositing the films on silicon wafers, with the perovskites tuned to capture wavelengths of light that silicon does not. On 10 September, Oxford PV announced that it was working with companies to make prototypes of these 'tandem' cells by 2015, and that this could boost silicon solar cells' efficiencies by one-fifth, so that they approach $30 \%$. Malinkiewicz's hope is to find a niche that silicon cannot fill: ultracheap, flexible solar cells that might not last for years, but could be rolled out on roof tiles, or used as a portable back-up power source.

There is another potential snag: perovskites contain a small amount of toxic lead, in a form that would be soluble in any water leaching through the cells' protection. Although Snaith and others have made films with tin instead, the efficiency of these cells is only just above $6 \%$.

Researchers say that many major electronics and chemicals firms are studying perovskites. Japan's space agency JAXA is also testing them for their potential to power satellites. But as Malinkiewicz has found, perovskites' lowcost, simple recipe means that anyone has a shot at commercializing them. "It is not just in the hands of the big chemical companies, or the silicon companies," says Mohammad Khaja Nazeeruddin, a chemist the Swiss Federal Institute of Technology in Lausanne. "It is everybody's technology." - 